\title{
Qualitative systemic review of randomized controlled trials on complementary and alternative medicine treatments in fibromyalgia
}

Julia Baranowsky • Petra Klose • Frauke Musial •

Winfried Häuser · Gustav Dobos · Jost Langhorst

Published online: 22 September 2009

(C) Springer-Verlag 2009

\section{Erratum to: Rheumatol Int}

DOI 10.1007/s00296-009-0977-5

Unfortunately the author name Winfried Haeuser was rendered wrongly. The correct name is Winfried Häuser.

The online version of the original article can be found under doi:10.1007/s00296-009-0977-5.

J. Baranowsky · P. Klose · F. Musial · G. Dobos · J. Langhorst ( $\square)$ Department of Internal Medicine,

Complementary and Integrative Medicine, Kliniken Essen-Mitte,

University Duisburg-Essen, Essen, Germany

e-mail: jost.langhorst@gmx.de

W. Häuser

Department of Internal Medicine I, Klinikun Saarbrücken,

Saarbrücken, Germany

W. Häuser

Department of Psychosomatic Medicine,

Technische Universität München, Munich, Germany 